\section{Editor-in-Chief \\ Barbara McLain - (retired Prof.) \\ University of Hawaii, USA}

The Israeli Journal of Aquaculture (IJA) is an interdisciplinary journal that is dedicated to sharing new research and tested applications of aquaculture

The IJA is devoted to scholarly articles for improved aquaculture practices and related industries

The IJA is a peer-reviewed, open-access, electronic journal

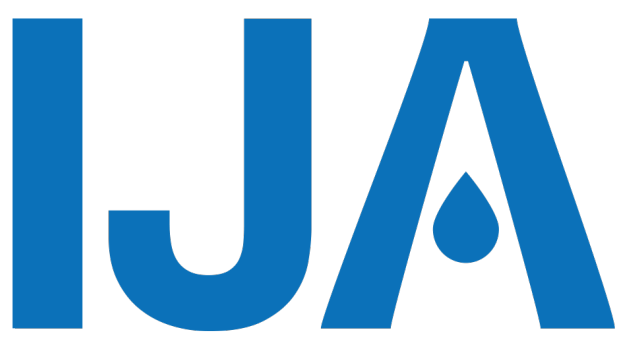

\section{The () Israeli Journal of Aquaculture}

An interdisciplinary online Open Access scientific journal

Published by the

\section{AquacultureHub}

A non-profit organization 501c3

http://www.aquaculturehub.org

in partnership with the

\section{University of Hawaii at Manoa} Library

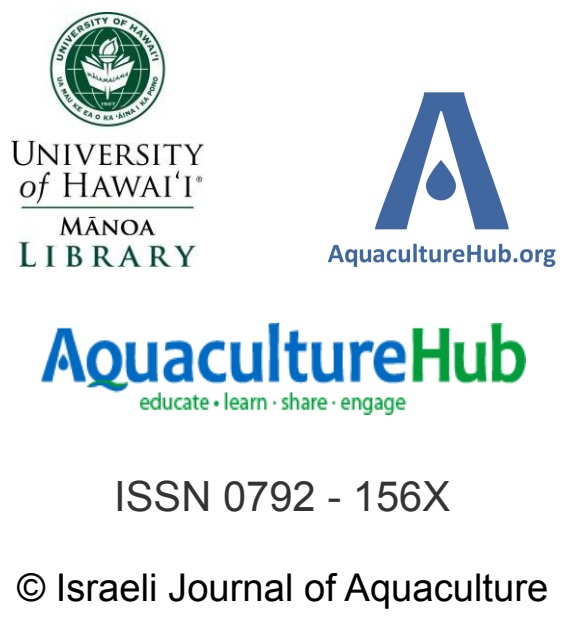


The Israeli Journal of Aquaculture - Bamidgeh, IJA_71.2019.1637, 7 pages

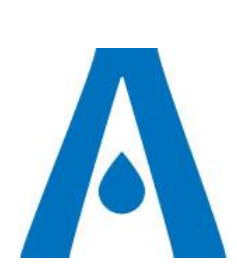

Produced by the AquacultureHub non-profit Foundation the $I J A$ is an open-access, scientific journal, published on http://www.aquaculturehub.org/group/israelijournalofaq uaculturebamidgehija

To read papers free of charge, please register online at the above website.

Sale of IJA papers is strictly forbidden.

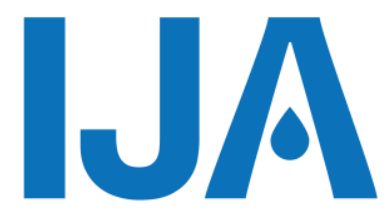

\title{
Withdrawal Period of Oxolinic Acid in Cobia (Rachycentron canadum): Validation of an LC-MS/MS Method
}

\author{
Chen RS ${ }^{1}$, Sheu SY2,3, Xue YJ ${ }^{4}$, Wang CY5,6, Liu $\mathrm{CH}^{7}$, Kuo TF" \\ Wang $\mathrm{JH}^{4 \#}$, Chou $\mathrm{CH}^{1 * *}$ \\ ${ }^{1}$ Graduate Institute of Veterinary Medicine, National Taiwan University, Taipei 106, \\ Taiwan \\ 2 School of Medicine, Chung Shan Medical University, Taichung 402, Taiwan \\ ${ }^{3}$ Department of Integrated Chinese and Western Medicine, Chung Shan Medical \\ University Hospital, Taichung 402, Taiwan \\ ${ }^{4}$ Department of Veterinary Medicine, National Chiayi University, Chiayi 600, Taiwan \\ ${ }^{5}$ Department of Cell Biology and Anatomy, College of Medicine, National Cheng Kung \\ University, Tainan 701, Taiwan \\ ${ }^{6}$ Institute of Basic Medical Sciences, College of Medicine, National Cheng Kung University, \\ Tainan 701, Taiwan \\ 7 Department of Veterinary Medicine, National Taiwan University, Taipei 106, Taiwan \\ ${ }^{8}$ Department of Post-Baccalaureate Veterinary Medicine, Asia University, Taichung 413, \\ Taiwan
}

Key words: Cobia; depletion study; oxolinic acid; LC-MS/MS

\begin{abstract}
Oxolinic acid (OXO) has been routinely used in aquaculture as both prophylactic and chemotherapeutic agents, principally against systemic bacterial infections. The residue depletion of OXO was investigated in cobia following multiple (5 days) in-feed dosing (30 and $60 \mathrm{mg} / \mathrm{kg}$ body weight/day) at $25^{\circ} \mathrm{C}$; we assessed OXO concentrations of liver and muscle (+skin) samples post-treatment for three weeks. The OXO residues were quantified using a validated ultra-high-performance liquid chromatographytandem mass spectrometry (UPLC-MS/MS) method and the results indicated recoveries of $86.6-95.8 \%$, with relative standard deviations (RSD) less than $8.5 \%$ for intra- and inter-day precisions. Within the range of $10-500 \mathrm{ng} / \mathrm{g}$, the calibration curves for all matrices presented a determination coefficient greater than 0.99. Limit of detection and quantification were estimated at 6 and $10 \mathrm{ng} / \mathrm{g}$, respectively. In order to account for the high variability of the residue data, a safety span corresponding to $50 \%$ of depletion time could be seen as appropriate. Considering a maximum residue limit (MRL) of $50 \mathrm{ng} / \mathrm{g}$ established by the Taiwan FDA for OXO in muscle with skin in natural proportions, a withdrawal period of 15 days was calculated for the sum of 10 day depletion time and 5-day safety span. These results revealed that the analytical method is developed for residue OXO and that the withdrawal period is appropriate.
\end{abstract}

* Corresponding author. Chung-Hsi Chou, e-mail: cchou@ntu.edu.tw

\# These authors contributed equally to this work 


\section{Introduction}

Aquaculture production is one of the most relevant sources of food protein production worldwide. Cobia (Rachycentron canadum), have aroused high interest in the aquaculture sector and scientific community, and are an emerging species for marine aquaculture from the Indo-Pacific waters to the southern Atlantic Ocean. Due to its favorable characteristics such as excellent meat quality, rapid weight gain, and easy spawning in captivity, in both domestic and international markets, technology for its culture has rapidly developed, including mass propagation, natural spawning of captive brood stocks, larval rearing techniques, nursery production in tanks, in open ponds, near shore and offshore cages in Taiwan (Liao et al., 2004). However, aquatic animal diseases have become a major constraint inhibiting their aquaculture production. The major infectious diseases affecting cobia include bacterial (pasteurellosis, vibriosis and streptococcosis), parasitic myxosporidea, Trichodina, Neobenedenia and Amyloodinium infestations, and viral lymphocystis (Liao et al., 2004). It is therefore important that therapeutic regimens are designed to maximize efficacy and minimize the risk of the development of resistant pathogens.

The benefit of improved productivity of veterinary drugs in comestible animals is often associated with the risk with drug residues in the tissues of treated animals at the time of slaughter or residues due to improper drug usage and failure to keep the withdrawal period. Thereby there is a legal requirement that drug concentrations do not persist at a level greater than those established as safe by the relevant regulatory authority in the country of origin (Beyene, 2016). The highest level is referred to as the maximum residue level (MRL), that is legally tolerated in food of animal origin when veterinary drugs are applied correctly.

Many of the countries involved in aquaculture have established mechanisms for veterinary drug approval and monitoring process in aquaculture. The European Medicine Agency (EMA) regulates the licensing and authorization of drug usage in aquaculture for countries under EU. The Codex Alimentarius Commission (CAC) is a joint FAO/WHO commission charged with developing standards for food safety with worldwide applications. In Taiwan the application of drugs in aquaculture is regulated by the 'Bureau of Animal and Plant Health Inspection and Quarantine (BAPHIQ)' to ensure safe and effective drugs/medicines for use in aquaculture.

Quinolones such as oxolinic acid (OXO), have a wide bioavailability, relative low toxicity, and favorable pharmacokinetics, and have been extensively used in aquaculture against bacterial infections including pasteurellosis, vibriosis and streptococcosis, etc. (Sellyei et al., 2009; Touraki et al., 2012; Dangwetngam et al., 2016), by increasing the concentration of drug-enzyme-DNA cleavage complexes and converting them into cellular toxins to turn them into bactericidals (Naeem et al., 2016). OXO is authorized in veterinary medicine for use in fin fish. The recommended doses are $12 \mathrm{mg} / \mathrm{kg}$ bw/day for up to 7 days for the treatment of gastro-enteritis due to Escherichia coli as set by European Medicines Agency (EMA) (2005). Permitted limits, MRL, of OXO are $100 \mathrm{ng} / \mathrm{g}$ allowed by the European Union (EU) established for muscle and skin in natural proportions (EU, 2009).

Though a number of residue studies for OXO have been published (Samuelsen et al., 1992; Guo and Liao, 1994; Rigos et al., 2003; Gonzalez et al., 2010), no previous work has investigated Cobia ( $R$. canadum). This study was undertaken to establish the withdrawal time following OXO treatments of cultured cobia to depletion below $50 \mathrm{ng} / \mathrm{g}$ in muscle and skin (the current tolerance level set by the Taiwan Food and Drug Administration (Taiwan FDA; TFDA) (TFDA, 2014). An effort was made to standardize the administration of the drug as well as the sampling and analytical protocol. The results obtained from these drug depletion trials suggest that public policies should impose regulations to ensure the proper use of OXO in cobia farms to further protect the health of consumers and maintain high export safety. 
Animal management.

\section{Materials and Methods}

Healthy cobia (mean weight, $140-170 \mathrm{~g}$ ) obtained from Fanliao aquafarms, (Pingtung, Taiwan), had been maintained at $25^{\circ} \mathrm{C}$ in fiber-glass-reinforced plastic (FRP) tanks of 1.8 ton $(1.2 \times 2.0 \times 0.75 \mathrm{~m})$ capacity with flow-through water systems during the experiments (Fig. 1). Fish were fed either medicated or nonmedicated commercial feed at the rate of $1 \%$ of fish body weight once each day in the morning. All animal studies were performed according to the protocols approved by the Institutional Animal Care and Use Committee at National Taiwan University (103-EL-20) and were carried out in accordance with the provisions of the EC Council Directive 2010/63/EU. Before the onset of drug administration, the cobia were acclimated for at least 2 weeks during which they were fed antibiotic-free commercial feed.

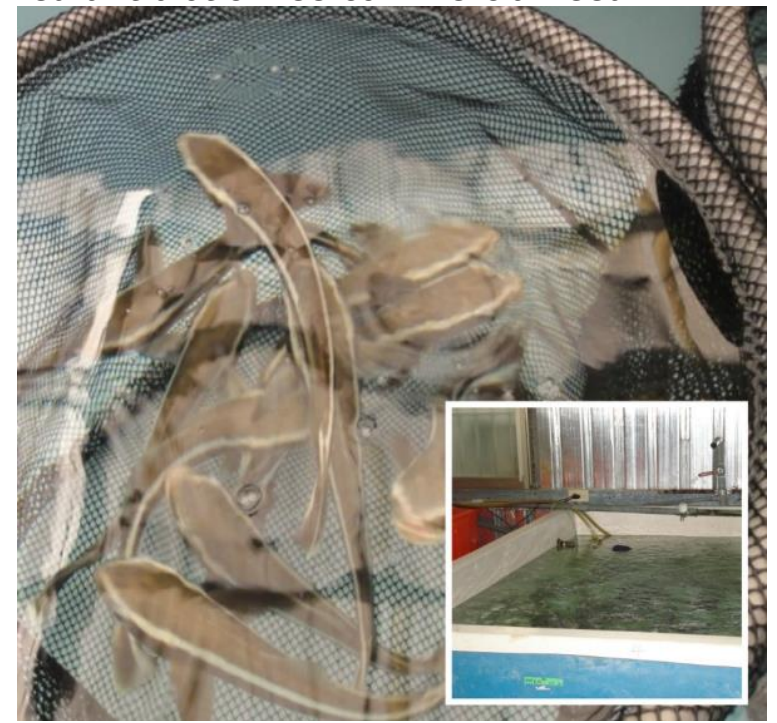

Fig. 1. Fiber-glass-reinforced plastics tank used for fish farming in residue depletion study.

Study design.

Medicated and unmedicated feed products (Oxalyl powder $\circledast$ ) were obtained from Juily Pharmaceutical Co., LTD (New Taipei City, Taiwan). Animals in the control group (no OXO added) were processed simultaneously. The OXO antibiotics concentration in feed was calculated to obtain an intake equivalent to a dose of 30 or $60 \mathrm{mg} / \mathrm{kg}$ of body weight. All medicated feeds were provided for 5 days. The low dose of $30 \mathrm{mg} / \mathrm{kg} / \mathrm{day}$ was selected based on empirical, positive impressions of clinical efficacy in aquatic species. The high dose of $60 \mathrm{mg} / \mathrm{kg} /$ day was chosen to monitor safety at the 2 dose levels within the trial. In this study, the experimental protocol included the sampling of fish at $1,3,5$, $7,10,14$ and 21 days after the 5-d medication period. Five fish were randomly sampled at each time point and sacrificed to analyze the residues of OXO in selected tissues (liver and muscle-skin samples). Muscle and the overlying skin were dissected from the midtrunk region near the lateral line. The sampled area was descaled prior to excision from the fish and were kept frozen at $-20^{\circ} \mathrm{C}$ until being analyzed.

Sample preparation.

Antimicrobials were extracted from aquatic tissue using an extraction procedure based on less organic solvent consuming methodology. A $5 \mathrm{~g}$ homogenate fish sample (muscle-skin/liver) was mixed with $25 \mathrm{~mL}$ of acetonitrile containing a $5 \%$ of methanol, and homogenized with a 12-speed osterizer blender (Oster, US) for $3 \mathrm{~min}$. Then $10 \mathrm{~g}$ of anhydrous sodium sulfate $\left(\mathrm{Na}_{2} \mathrm{SO}_{4}\right)$ was added, and the mixture was shaken using a Cute Mixer (CM-1000; Eyela, Japan) for 10 min and centrifuged (5804R, Eppendorf, Germany) at $3,500 \mathrm{xg}$, for $10 \mathrm{~min}$ at $4^{\circ} \mathrm{C}$. The supernatant was then transferred into a clean tube. The extraction procedure was performed twice; then the two extracts were combined and transferred into a separatory funnel and $30 \mathrm{~mL}$ of $n$-hexane saturated with acetonitrile was added to the solution and the contents were shaken vigorously for $3 \mathrm{~min}$ in a 
reciprocating shaker. The acetonitrile layer was then transferred to a vacuum rotary evaporator flask, and concentrated to dryness at $40^{\circ} \mathrm{C}$. Finally, the residue was redissolved in methanol (50\%) to make exactly $1 \mathrm{~mL}$ of sample solution, and this was filtered through a $0.22 \mu \mathrm{m}$ nylon membrane filter, followed by LC-MS/MS analysis.

Determination of OXO residues in cobia by qualitative LC-MS/MS.

The chromatographic analyses were performed on an Acquity UPLC system, and separations were achieved using an Acquity UPLC $®$ HSS C18 column $(1.7 \mu \mathrm{m}, 2.1 \times 100$ $\mathrm{mm}$; Waters, US). The column temperature was set at $35^{\circ} \mathrm{C}$. The mobile phase flow rate was fixed at $0.2 \mathrm{~mL} / \mathrm{min}$ and the following program was applied for the elution:

$0 \mathrm{~min}, 96 \% \mathrm{~A} ; 0-2 \mathrm{~min}, 96-95 \% \mathrm{~A} ; 3.0-6.0 \mathrm{~min}, 80-75 \% \mathrm{~A} ; 6.0-8.6 \mathrm{~min}, 75-73 \% \mathrm{~A}$; 8.6-14.5 min, $73-63 \% A_{;} ; 14.5-14.7 \mathrm{~min}, 63-0 \% \mathrm{~A} ; 14.7-18.7 \mathrm{~min}, 0-96 \% \mathrm{~A}$ and 18.7-20.0 min, 96\% A. Deionized water (DI water):formic acid (99.9:0.1, v/v) as eluent A and methanol: formic acid $(99.9: 0.1, \mathrm{v} / \mathrm{v})$ as solvent B. Injection volume was $10 \mu \mathrm{L}$.

Mass spectrometry analyses were carried out using a Waters Acquity TQS ${ }^{\mathrm{TM}}$ Micromass Quattro Ultima triple-quadrupole MS quadrupole equipped with an electrospray ion source (Micromass, Manchester, UK). The instrument was operated using an electrospray (ESI) source in positive mode with the following parameters: $3.3 \mathrm{kV}$ capillary voltage, 25 $\mathrm{V}$ cone voltage, $120^{\circ} \mathrm{C}$ source temperature, $450^{\circ} \mathrm{C}$ desolvation temperature, $100 \mathrm{~L} / \mathrm{h}$ cone gas flow and $800 \mathrm{~L} / \mathrm{h}$ desolvation gas. The OXO isomers were fragmented using collision-induced dissociation and the multiple reaction monitoring (MRM) transitions $\mathrm{m} / \mathrm{z}$ $=262>244, \mathrm{~m} / \mathrm{z}=262>216$ and $\mathrm{m} / \mathrm{z}=262>160$ were monitored (m/z, mass-tocharge ratio). Data acquisition was performed using MassLynx $\vee 4.1$ software with the Quanlynx program (Waters).

Quality control.

The method was validated with the following performance parameters: linearity and linear range, detection and quantitation limits. The intra-day and inter-day precision of the method, expressed as the relative standard deviation (RSD) of known concentrations measurements, were assessed by using blank fish samples fortified with OXO at three concentrations of 10,50 , and $100 \mathrm{ng} / \mathrm{g}$. Five replicates determination of each concentration was conducted during routine operation of the system over a period of five consecutive days. Internal quality controls were used, e.g., a blank extract was used to identify false positive results obtained through contamination from the extraction process, instruments, or chemicals, and to identify possible matrix interferences. Another blank sample was spiked with OXO at $10 \mathrm{ng} / \mathrm{g}$ (muscle) and $20 \mathrm{ng} / \mathrm{g}$ (liver) and the extraction efficiencies were assessed. A matrix-matched calibration curve was prepared daily from the blank matrix extract.

\section{Methods validation}

\section{Results}

The developed procedure was designed to obtain qualitative and quantitative surveillance information about the quinolone antibiotic and to simultaneously analyze the same analytical protocol. The identification of OXO by LC-ESI-MS/MS obtained from fortified blank fish muscle-skin and liver samples with retention times ranging from 18.302 to 18.363 minutes. Linear regression coefficients $(R(2))$ of matrix-match calibration standard curves established for quantification were higher than 0.9989 , which is adequate for analytical purposes. Inter-assay precision with percentage relative standard deviations (RSD) was in the range 2.3-8.5\%. Intra-day precision (RSD) was lower than $5.6 \%$. The limit of detection (LOD) was $6 \mathrm{ng} / \mathrm{g}$ given by signal-noise ratio $\geq 3(\mathrm{~S} / \mathrm{N}$ ) and the limit of quantification ( $L O Q, S / N \geq 10$ ) was estimated at $10 \mathrm{ng} / \mathrm{g}$. Average recoveries and extraction efficiency were synonyms of the fortified OXO at two concentrations 10 and $20 \mathrm{ng} / \mathrm{g}$ were between $86.6 \%$ and $95.8 \%$, with RSD in the range of $1.4-4.2 \%$.

Residue depletion studies

In the 5-day repeated dose study in cobia, OXO was performed using doses of 30 and $60 \mathrm{mg} / \mathrm{kg}$ bw/day in the low- and high-dose groups. Results for OXO depletion from fish tissues (muscle plus skin in natural proportions and liver) at different times are shown in Table 1. The OXO concentrations were below the MRL $(50 \mathrm{ng} / \mathrm{g})$ established by the Taiwan FDA: range $30-40 \mathrm{ng} / \mathrm{g}$ in the muscles (at day 5), and $10-30 \mathrm{ng} / \mathrm{g}$ in the liver 
(at day 5), respectively, for cobia in the low-dose groups; whereas range $10-30 \mathrm{ng} / \mathrm{g}$ in the muscles (at day 7), and 20-30 ng/g in liver (at day 10), respectively, in the highdose groups.

Table 1. Oxolinic acid depletion at different times in cobia tissues.

\begin{tabular}{|c|c|c|c|c|c|c|}
\hline \multirow{2}{*}{$\frac{\text { Time }}{\text { day }^{2}}$} & \multicolumn{3}{|c|}{ OXO concn $(\mathrm{ng} / \mathrm{g})^{1}$ (low-dose group) } & \multicolumn{3}{|c|}{ OXO concn (ng/g) (high-dose group) } \\
\hline & Control & Muscle + skin & Liver & Control & Muscle + skin & Liver \\
\hline 1 & $\mathrm{ND}^{3}$ & $62 \pm 11.7$ & $64 \pm 20.6$ & ND & $202 \pm 44.5$ & $264 \pm 95.4$ \\
\hline 3 & ND & $44 \pm 20.6$ & $50 \pm 11.0$ & ND & $170 \pm 23.7$ & $33 \pm 10.9$ \\
\hline 5 & ND & $34 \pm 4.9$ & $18 \pm 7.5$ & ND & $72 \pm 11.7$ & $42 \pm 14.7$ \\
\hline 7 & ND & $16 \pm 4.9$ & $12 \pm 4.0$ & ND & $22 \pm 7.5$ & $40 \pm 11.0$ \\
\hline 10 & ND & ND & ND & ND & $34 \pm 8.0$ & $24 \pm 4.9$ \\
\hline 14 & ND & ND & ND & ND & $6.0 \pm 4.9$ & $20 \pm 0.0$ \\
\hline 21 & ND & ND & ND & ND & ND & ND \\
\hline
\end{tabular}

${ }^{1}$ Values are means \pm SDs for 5 samples.

2 Day after the last administration of medicated food.

${ }^{3}$ Not determined.

\section{Discussion}

The results in this work show that OXO bioacumulate at high concentrations in the muscle and liver, even though in the liver samples the concentrations fell below the MRL. In addition, the depletion time results agree with those reported by other researchers for depletion behavior of OXO in different species. In the case of a single oral dose of 40 $\mathrm{mg} / \mathrm{kg}$ of OXO in orange-spotted grouper E. coioides, Guo and Liao (1994), found the elimination half-life $\left(t_{1 / 2}\right)$ value of $15.1 \mathrm{~h}$ at $24^{\circ} \mathrm{C}$, and OXO absorption was complete in about $12 \mathrm{~h}$ following dosing as well as the highest concentrations were measured in the kidney followed by the liver, muscle and serum; afterward, its concentrations declined below the MRL 10 days following medication.

Furthermore, another study showed that following OXO multiple medications of 25 $\mathrm{mg} / \mathrm{kg} /$ day to salmon (Salmo salar L.) for ten days at $9^{\circ} \mathrm{C}$, depletion times after treatment ceased for the residues of OXO concentrations which fell below the MRL of 50 $\mathrm{ng} / \mathrm{g}$ after 12 days in the liver, followed by the muscle and plasma (Samuelsen et al. 1992). Similarly, another study found that the distribution and elimination of OXO in gilthead sea bream (S. aurata) and sharpsnout sea bream (D. puntazzo) following oral administration of $30 \mathrm{mg} / \mathrm{kg} /$ day on ten consecutive days at $19^{\circ} \mathrm{C}$ (Rigos et al., 2003). Elimination $t_{1 / 2}$ were estimated to be 11-14 and $11-19 \mathrm{~h}$ in tissues of gilthead sea bream and sharpsnout sea bream, respectively. OXO concentration in sparids peaked on day 4, with highest concentrations in liver, followed by bile, skin, muscle and plasma, where its concentrations diminished 12 days after ceasing treatment.

As for differences in tissue distributions, it is known that biological factors affecting drug distribution are blood flow to tissue and capillary porosity (Sim, 2015). Drugs rapidly enter high perfused tissues with discontinuous capillaries (e.g. liver), while drug distribution into the tissues with low perfusion rates and with continuous capillaries (e.g. skin) is slow (Hamamoto and Mizuno, 2017). Higher OXO concentrations in muscle-skin samples than those in liver samples at the withdrawal period in the present study seem to be caused by slow drug transfer between muscle, skin, and plasma depending on the low blood perfusion in cobia muscle and skin.

Since marketing authorization applications for veterinary medicinal products for use in food producing species must include an indication of the withdrawal period, it is recommended to determine withdrawal period at the time point where the concentrations of residues in edible tissues fall below the respective MRL (EMA, 2018) for muscle and liver samples $(50 \mathrm{ng} / \mathrm{g})$. Also, the estimation of a safety span should be calculated from a half of tissue depletion time. Therefore, in order to account for the high variability of the residue data, this safety span corresponds to $50 \%$ of the 10 -day depletion time; the conclusive approach would then result in a withdrawal period of 15 days as in the present study.

Our results agree with the general trend described by the aforementioned works, as on day 7 after treatment we found residue concentrations of $22 \pm 7.5 \mathrm{ng} / \mathrm{g}$ in cobia 
muscle-skin samples, whereas in livers (at higher doses) these were of $24 \pm 4.9 \mathrm{ng} / \mathrm{g}$. Concentrations declined and fell below the MRL on day 10 following the last administration. It can be assumed that warmwater fish are likely to process drugs faster than coldwater species. Higher ambient temperatures and/or salinity may increase xenobiotic metabolism and elimination rates (Gonzalez et al., 2010), for example, OXO has been shown to be eliminated much faster in fish in seawater than those in fresh water (Ishida, 1992).

In conclusion, the analytical method for residual OXO in cobia liver and muscle was presented in our study. Our results determined by analytical methods prove that the 10day depletion period in cobia administered medicated feed at the maximum dose and administration period of OXO (60 mg/kg/day for 5-day) is appropriate to ensure that OXO concentrations are below the MRL $(50 \mathrm{ng} / \mathrm{g})$. The depletion behavior we have detailed in this work provides data supporting more prudent use of OXO in cobia and suggests a possible withdrawal period of 15 days (10-day depletion time +5 -day safety span) after treatment. It therefore aids in the design and application of new policies of antimicrobial surveillance.

\section{Acknowledgements}

The authors kindly thank the Council of Agriculture, Taiwan, for its financial support (Project 103AS-10.1.2-BQ-B5)

\section{References}

Beyene, T., 2016. Veterinary drug residues in food-animal products: Its risk factors and potential effects on public health. J. Veterinar. Sci. Technol., 7(1):285.

Codex, 2016. Codex Alimentarius Commission. Circular letter 2016/42-RVDF Appendix 1: Database on countries' needs for MRLs.

Dangwetngam, M., Suanyuk, N., Kong, F., Phromkunthong, W., 2016. Serotype distribution and antimicrobial susceptibilities of Streptococcus agalactiae isolated from infected cultured tilapia (Oreochromis niloticus) in Thailand: Nine-year perspective. J. Med. Microbiol., 65(3):247-254.

EMA (European Medicines Agency), 2005. Committee for medical products for veterinary use: Oxolinic acid, Summary report (5), EMEA/CVMP/41090/2005-Final.

EMA (European Medicines Agency), 2018. Committee for medical products for veterinary use: Guideline on determination of withdrawal periods for edible tissues, EMEA/CVMP/SWP/735325/2012.

EU (European Union), 2009. Commission Regulation No 37/2010 on pharmacologically active substances and their classification regarding maximum residue limits in foodstuffs of animal origin.

Gonzalez, R.R., Fernandez, R.F., Vidal, J.L.M., Muros, M.J.S., Frenich, A.G., 2010. Depletion of veterinary drugs used in aquaculture after administration in feed to gilthead seabream (Sparus aurata). J. Food Prot. 73(9):1664-1670.

Guo, J.J., Liao, I.C., 1994. Pharmacokinetics of oxolinic acid in orange-spotted grouper, Epinephelus coioides, after single oral administration at $24^{\circ} \mathrm{C}$. J. Fish Soc. Taiwan, 21(3):263-272.

Hamamoto, K., Mizuno, Y., 2017. LC-MS/MS measurement of ampicillin residue in chicken tissues at 2 days after in-feed administration. J. Vet. Med. Sci., 79(3):474-478.

Ishida, N., 1992. Tissue levels of oxolinic acid after oral or intravascular administration to fresh water and sea water rainbow trout. Aquaculture, 102(1-2):9-15.

Liao, I.C., Huang, T.S., Tsai, W.S., Hsueh, C.M., Chang, S.L., Leaño, E.M., 2004. Cobia culture in Taiwan: current status and problems. Aquaculture, 237(1-4):155-165.

Naeem, A., Badshah, S.L., Muska, M., Ahmad, N., Khan, K., 2016. The current case of quinolones: Synthetic approaches and antibacterial activity. Molecules, 21(4):268.

Rigos, G., Nengas, I., Alexis, M., Tyrpenou, A.E., Troisi, G.M., 2003. Tissue distribution and residue depletion of oxolinic acid in gilthead sea bream (Sparus aurata) and sharpsnout sea bream (Diplodus puntazzo) following multiple in-feed dosing. Aquaculture, 224(1/4):245-256. 
Samuelsen, O.B., Lunestad B.T., Husevag, B., Holleland, T., Ervik, A., 1992. Residues of oxolinic acid in wild fauna following medication in fish farms. Dis. Aquat. Org., 12:111-119.

Sellyei, B., Varga, Z., Szentesi-Samu, K., Kaszanyitzky, E., Magyar, T., 2009. Antimicrobial susceptibility of Pasteurella multocida isolated from swine and poultry. Acta Vet. Hung., 57(3):357-567.

Sim, D.S.M., 2015. Drug distribution. In: Chan, Y.K., Ng, K.P. and Sim, D.S.M. (eds.): Pharmacological basis of acute care, 1st ed. Springer International Publishing, Cham, Switzerland, pp.27-36.

TFDA (Taiwan Food and Drug Administration), 2014. Standards for veterinary drug residue limits in foods, Food No. 1031300872 Amended.

Touraki, M., Niopas, I., Karagiannis, V., 2012. Treatment of vibriosis in European sea bass larvae, Dicentrarchus labrax L., with oxolinic acid administered by bath or through medicated nauplii of Artemia franciscana (Kellogg): efficacy and residual kinetics. J. Fish Dis., 35(7):513-522. 